\title{
Gender and racial differences in risk factors for sexually transmitted diseases among justice-involved youth
}

\author{
Richard Dembo' \\ Kristina Childs ${ }^{2}$ \\ Steven Belenko ${ }^{3}$ \\ James Schmeidler ${ }^{4}$ \\ Jennifer Wareham ${ }^{5}$ \\ 'University of South Florida, \\ Department of Criminology, Tampa, \\ FL, USA; ${ }^{2}$ University of New Orleans, \\ Department of Psychology, New \\ Orleans, LA, USA; ${ }^{3}$ Department of \\ Criminal Justice, Temple University, \\ Philadelphia, PA,USA; ${ }^{4}$ Departments \\ of Psychiatry and Biomathematical \\ Sciences, Mt. Sinai School of Medicine, \\ New York, NY, USA; ${ }^{5}$ Department \\ of Criminal Justice, Wayne State \\ University, Detroit, MI, USA
}

Correspondence: Richard Dembo Department of Criminology, University of South Florida, 4202 E. Fowler Ave., Tampa, FL 33620, USA

Tel +I (8I3) 93I-3345

Email jac@gate.net.
This article was published in the following Dove Press journal:

Neurobehavioral HIV Medicine

18 November 2009

Number of times this article has been viewed

\begin{abstract}
Gender and racial differences in infection rates for chlamydia and gonorrhea have been reported within community-based populations, but little is known of such differences within juvenile offending populations. Moreover, while research has demonstrated that certain individual-level and community-level factors affect risky behaviors associated with sexually transmitted disease (STD), less is known about how multi-level factors affect STD infection, particularly among delinquent populations. The present study investigated gender and racial differences in STD infection among a sample of 924 juvenile offenders. Generalized linear model regression analyses were conducted to examine the influence of individual-level factors such as age, offense history, and substance use and community-level factors such as concentrated disadvantage, ethnic heterogeneity, and family disruption on STD status. Results revealed significant racial and STD status differences across gender, as well as interaction effects for race and STD status for males only. Gender differences in individual-level and community-level predictors were also found. Implications of these findings for future research and public health policy are discussed.
\end{abstract}

Keywords: juvenile delinquents, sexually transmitted diseases, gender differences, personal risk factors, community risk factors

Sexually transmitted diseases (STDs) represent a continuing, major public health problem, particularly among female and minority adolescents who are disproportionately at risk of infection. A recent report from the Centers for Disease Control and Prevention, ${ }^{1}$ highlights the importance of this public health crisis. In 2007, 1.1 million Chlamydia trachomatis diagnoses were reported in the US, a $7.5 \%$ increase over $2006 .{ }^{1}$ In 2007 , women were almost three times more likely to be infected with chlamydia than men, with females ages 15 to 19 and 20 to 24 reporting the highest rates of infection across age and gender groups. ${ }^{1}$ Certain racial and ethnic groups also demonstrated very high rates of infection, with African-Americans and Hispanics having rates of infection that were 8.6 and 2.9 times higher, respectively, than the rates of infection among whites. ${ }^{1}$ Yet, CDC estimates that over half of new cases of chlamydia are undiagnosed and unreported each year. ${ }^{2}$

Gonorrhea (Neisseria gonorrhoeae), the second most frequently reported infectious disease in the US, remained stable in 2007, but at an unacceptably high level, with 355,991 cases being reported. ${ }^{1}$ In general, gonorrhea infection rates were similar across gender groups in 2007, with adolescent females aged 15 to 19 reporting the highest rates. ${ }^{1}$ Similar to chlamydia, racial and ethnic disparities in infection were reported by 
the CDC, with African-Americans and Hispanics having rates of infection that were 19.1 and 2.0 times higher, respectively, than those of whites. ${ }^{1}$

Although they comprise about a quarter of the sexually active population, youths aged 15 to 24 account for about half of all STD cases. Serious as the STD situation is among youths in the general population, it is an even greater issue among youths involved in the juvenile justice system. For example, chlamydia and gonorrhea rates among male adolescent detainees have been found to be many times greater than the general population in the same age range. ${ }^{1}$ More recently, the $\mathrm{CDC}^{1}$ reported a $6.9 \%$ median state STD positive rate for females aged 15 to 24 tested at family clinics, whereas the median state positive rate for adolescent females tested in juvenile correctional facilities was over twice that (14.8\%). These high rates of STD infection among juvenile delinquents highlight the need to address this critical public health concern among this population. ${ }^{3}$

A number of studies on adolescent offenders have also documented marked variation in STD prevalence rates, particularly across race and gender. In 2007, girls represented about $30 \%$ of juveniles arrested nationally. ${ }^{4}$ While juvenile arrests rates overall continued to decline, this decline was generally slower for girls compared to boys, and, in some cases such as assault, arrest rates for girls increased compared to boys. ${ }^{4}$ Female juvenile offenders are consistently found to have disproportionately high STD rates compared to male juvenile offenders. ${ }^{5,6}$ In 2006, for example, Joesoef et al estimated that chlamydia infection rates ranged from $13.0 \%$ to $24.7 \%$ in incarcerated adolescent female populations, and from $4.8 \%$ to $8.1 \%$ among incarcerated male adolescents; gonorrhea infection rates ranged from $4.5 \%$ to $7.3 \%$ among incarcerated females and from $0.9 \%$ to $6.7 \%$ for males in the same population.

Minority youth, particularly African-Americans, are disproportionately represented in the juvenile offender population. ${ }^{4}$ This disparity exists when looking at STD infection. On average, minority juvenile offenders display higher rates of STD infection compared to white juvenile offenders. Based on samples of incarcerated adolescents, ${ }^{5-7}$ reported substantially higher STD rates for minority detainees compared to white detainees. Kahn et $\mathrm{al}^{5}$ tested juvenile offenders for chlamydia and gonorrhea in 14 different US detention centers. The chlamydia positivity rate for AfricanAmerican detainees was $9.9 \%$ compared to $5.8 \%$ for white adolescent detainees. Similarly, the gonorrhea positivity rate was nearly three times higher for African-American detainees compared to white detainees.
Both race and gender have multiple correlates that may account for these differences, including cultural expectations, experience of sexual victimization, socio-economic status, access to community resources, education, and poor family environment. ${ }^{8}$ Thus, as these previous studies suggest, obtaining an accurate understanding of the nature of STD infection among juvenile offenders requires accounting for race and gender. However, these previous studies fall short of a) examining variations in STD prevalence across subgroups of offenders based on race and gender, and b) identifying the risk factors that account for these demographic differences. Accordingly, this study represents a first and necessary step towards understanding the demographic differences in STD infection among juvenile offenders. Specifically, using a sample of newly arrested juvenile offenders, the current study examines the association among a number of individual and community-level factors and STD status (ie, testing positive or negative for STDs) across race and gender.

\section{Individual-level factors}

In addition to race and gender, several additional individuallevel characteristics have been shown to be consistent predictors of STD status among juvenile offenders. Specifically, age, criminal involvement, and substance use have long been considered important risk factors for STD prevalence among adolescent offenders. On average, older juvenile offenders are more likely to test STD positive. ${ }^{9,10}$ However, this relationship is somewhat inconsistent when examined across gender. For example, Mertz et $\mathrm{al}^{6}$ found that male detainees aged 15 to 19 years were more likely to test positive for chlamydia and gonorrhea, compared to male detainees aged 10 to 14 . On the other hand, female detainees aged 10 to 14 were more likely to test positive for gonorrhea but less likely to test positive for chlamydia than female detainees aged 15 to 19 . Kahn et $\mathrm{al}^{5}$ found that older male detainees were significantly more likely to test positive for chlamydia. However, tests for chlamydia among the female detainees did not reveal significant age differences.

Research has also provided strong support for the link between juvenile offending and STDs. In particular, adolescents who report serious forms of delinquent behavior (eg, violent offending) and/or a greater frequency of involvement in criminal behavior are significantly more likely to report unsafe sexual practices and test STD positive, compared to less serious offenders and/or nonoffenders. ${ }^{11-15}$ However, the strength of this relationship across racial and gender subgroups of offenders has not been extensively studied. 
Similarly, a wealth of research has documented a strong and consistent association between substance use and sexual risk behavior, including STD infection. In particular, juvenile offenders who report more serious forms of substance use (eg, cocaine), a greater frequency of substance use (eg, chronic users), and the use of substances prior to or during sexual activity are significantly more likely to test STD positive, compared to juvenile offenders who do not use substances. ${ }^{10,12,16-18}$ Although these relationships are quite robust across race and gender, a number of studies have suggested that the association between substance use and STD infection may vary across demographic subgroups. ${ }^{10,18,19}$

In general, the large majority of previous studies that have examined STD infection among adolescent offenders focused solely on individual-level variables. However, merely examining individual-level predictors of STDs limits our understanding of this complex, multi-dimensional public health issue, and prevents insight into how multiple level factors influence sexual behavior and health. ${ }^{20}$ Indeed, in their recent review of risk factors associated with STD/HIV infection, DiClemente et $\mathrm{al}^{21}$ emphasized the importance of examining multi-level and multi-dimensional risk factors for STDs and called for a more ecological approach to examining this issue. Thus, it is important to consider the relative influence of both individual and community-level risk factors on STD prevalence, as well as identify differences in these relationships across demographic characteristics.

\section{Community-level factors}

Increasingly, researchers and epidemiologists are recognizing the important roles that community contexts and structural factors play in determining STD and other health risk behaviors among adolescents. ${ }^{21,22}$ In particular, it is important to consider the social context in which individual-level factors are operating. The characteristics of the neighborhood setting in which an adolescent resides provide a context that has the potential to influence health risk behavior, and to inform the development and expansion of accessible and effective community-based STD prevention and treatment services.

Several explanatory models have been proposed to account for community variations in social and health related ills. One contextual perspective, in particular, that has articulated an empirically viable explanation for how variation in community factors explain variation in delinquency and health consequences is social disorganization theory. ${ }^{23-25}$ From a social disorganization perspective, neighborhood disadvantage, such as economic inequality, family disruption, racial heterogeneity, and residential mobility, inhibits the general effectiveness of local institutions (eg, schools, churches, health providers) and prevents the development and maintenance of social support and cohesion. More specifically, neighborhoods characterized by higher levels of poverty, economic inequality, and unemployment are less able to provide effective resources and institutions for their residents; hence, they demonstrate higher levels of social ills. Communities marked by racial and ethnic variation are less likely to experience social cohesion and develop strong mechanisms of social control due to potential language and cultural barriers. Neighborhoods with higher levels of residential mobility experience weakened social control mechanisms because high population turnover leads to inconsistent values and norms and low investment in the community. Social control mechanisms are also threatened by higher levels of family disruption (ie, divorce, single parent households) and unsupervised youth. Family disruption is associated with lower family income, longer work hours for single parents, and decreased parental supervision of children. Unsupervised children are more likely to become involved in antisocial behavior, including risky sexual practices. All of the aforementioned factors work to undermine social cohesion and collective efficacy within communities and mitigate public health problems.

Social disorganization theory has received strong empirical support for explaining neighborhood variation in crime and delinquency. ${ }^{26}$ The theory has also demonstrated promise in explaining variation in neighborhood levels of risky sexual behavior. In particular, poverty and economic inequality have been found to be associated with high rates of sexual activity, pregnancy, premarital births, abortions, and resistance to contraception use among adolescents..$^{27-31}$ The racial composition of neighborhoods, specifically residing in neighborhoods with higher proportions of minority populations, has also been linked with risky sexual behavior. ${ }^{32-36}$ Other studies have found residential instability is positively related to premarital sex, premarital pregnancy, and multiple sexual partners. ${ }^{29,35,37,38}$

A few studies have examined the association between community characteristics and STD infection rates among adolescents. These studies suggest that disadvantaged communities have higher STD rates. ${ }^{39,40}$ Additionally, adolescents living in urban or inner-city settings have higher STD prevalence rates, than youths living in rural or suburban areas. ${ }^{41}$ Overall, these studies suggest that adolescents residing in more disadvantaged neighborhoods engage in greater risks 
associated with sexual activity, which consequently place them at increased risk for contracting STDs.

\section{The current study}

The present study sought to contribute to the existing body of public health and criminological research in two important ways. First, to date, the large majority of studies examining STD prevalence among juvenile offenders are based on incarcerated samples which consist of the most high-risk, criminally involved adolescents. Given that roughly $80 \%$ of the adolescents are released back to the community following arrest, the generalizability of the results of these studies to the entire juvenile offending population is questionable. ${ }^{42}$ The sample used in the current study involves newly arrested juvenile offenders and provides a unique opportunity to assess the relative influence of a number of risk factors on STD status among a diverse sample of juvenile offenders, including youths released back to the community following arrest and youths placed in secure detention.

Second, this study examines the combined and separate influence of individual-level and community-level predictors on STD status within gender and race groups. Since STD prevalence rates differ substantially by gender and by race, this study examines the collective and separate influences on STD status for each gender, and whether there is a distinction between African-American and non-African-American youths in each gender. Identifying specific risk factors associated with STD status outcomes and noting risk factors that differ between African-American and non-AfricanAmerican youths can provide valuable information towards the development of interventions targeted by gender and race to reduce risk behaviors and STD infection. There are undoubtedly important inter-relationships among the risk factors, so that for the purpose of understanding the relationship of all the risk factors to STD infection, it would be necessary to assess the effect of each risk factor controlling for the others. Nonetheless, the simple associations of each risk factor with STD, or with race differences in STD, are more relevant for informing different intervention strategies to be targeted to race and gender subgroups.

\section{Methods}

\section{Sample}

Data for this study came from a National Institute of Drug Abuse (NIDA) funded research project that focused on: 1) identifying STD prevalence rates among newly arrested juvenile offenders, 2) assessing the feasibility of providing front-end STD services to juvenile offenders, and 3) providing free treatment to STD positive youth. ${ }^{3}$ The project involved a successful collaboration of the Hillsborough County Juvenile Assessment Center (HJAC), the Hillsborough County Sheriff's Office (HCSO), the Florida Department of Health (DOH), Hillsborough County Health Department (HCHD), and the Florida Department of Juvenile Justice (DJJ).

All study protocols were approved and monitored by the investigators' Institutional Review Boards (IRB). In order to comply with requirements of the DHHS Office of Human Research Protections (OHRP) and the project IRBs, project research staff could not have direct contact with the youths. In addition, Florida state law protects the confidentiality of youth aged 12 or older who are tested for STDs, even from their parents, and parental consent for an STD test is not required. After receiving National Institute of Health human subjects certification, HJAC staff were trained by the authors to: (1) conduct STD pre-test counseling of project eligible youth, (2) obtain consent to split their urine specimens for STD testing, and (3) complete a Supplemental Contact Form on consenting youths (to assist HCHD Disease Intervention Specialist staff in locating infected youths for treatment). The agency employing HJAC staff, and coordinating HJAC operations, provided de-identified data for analysis. In addition to OHRP approval, all recruitment and consent procedures were reviewed and approved by the relevant IRBs.

Participants were newly arrested juveniles processed at the HJAC (a centralized intake facility) between June 19 and September 30, 2006. During the recruitment period, youths processed at the HJAC were asked to voluntarily participate in the project by consenting to have their urine specimens, which are provided for drug testing as part of the standard HJAC processing protocol, split tested for chlamydia and gonorrhea. The sample was stratified by gender to ensure appropriate representation of female offenders. A total of 759 males and 634 females were recruited and assessed by HJAC assessment staff. Among these, $82.6 \%$ of both the males and females agreed to provide a urine specimen for drug testing. Of those providing a urine specimen, $80.7 \%$ of the males and $84.4 \%$ of the females also consented to have their urine split tested for chlamydia and gonorrhea. Thus, the final, original study sample consisted of 506 males and 442 females who consented to have a drug and STD urinalysis (UA). Among the females in the sample, approximately half were African-American, $43 \%$ were white, and $7 \%$ were white Hispanic. Among the males in the sample, approximately half were also African-American, $34 \%$ were white, $10 \%$ were white Hispanic, $1 \%$ was black Hispanic, and less than $1 \%$ was 
some other race/ethnicity. Due to inconsistencies in HJAC staff recording Hispanic ethnicity, the sample was subdivided into African-American versus non-African-American for racial comparisons in this study.

The addresses of the youths were geocoded to permit multilevel analyses. After interactively matching the partial and non-matching addresses, 924 of the youths (97.5\%) were successfully geocoded in a six-county area, covering residential locations within Hillsborough County, Florida and its five adjacent counties (Hardee, Manatee, Pasco, Pinellas, and Polk). As a result of the geocoding process, the sample involved in this paper included 491 males and 433 females, residing in 221 census tracts. ${ }^{a}$

\section{Individual level measures}

\section{Testing for chlamydia and gonorrhea}

A non-invasive, FDA-approved, urine-based nucleic acid test, GenProbe APTIMA Combo 2 Assay, was used to test for chlamydia and gonorrhea. The sensitivity and specificity of the GenProbe urine-based chlamydia test are $95.9 \%$ and $98.2 \%$, respectively, and for gonorrhea they are $97.8 \%$ and 98.9\%, respectively. ${ }^{43}$ Each youth's STD results were recoded into a dichotomous variable representing positive for any STD (ie, chlamydia, gonorrhea, or both) $=1$ or negative for both STD tests $=0$.

\section{UA drug use data}

At the testing lab, the split urine specimens were also tested for drugs using the EMIT procedure. The cutoff levels for a positive for each drug were: marijuana ( $50 \mathrm{ng} / \mathrm{mL}$ of urine) and cocaine ( $300 \mathrm{ng} / \mathrm{mL}$ of urine). Both drug test measures were coded $1=$ positive and $0=$ negative. $^{\mathrm{b}}$

\section{Post HJAC placement and charge level}

In accordance with Florida State law, a Detention Risk Assessment Instrument (DRAI) must be completed by a trained HJAC screener on each youth brought to the HJAC on a delinquency charge. ${ }^{44}$ The DRAI takes into consideration the youth's most serious current offense, other current offenses and pending charges, prior offense history, current legal status, and aggravating or mitigating circumstances. On the basis of this information, each youth is assigned a point score.

For the non-geocoded youths, $2(0.2 \%)$ provided an out of state address, $8(0.8 \%)$ provided addresses with missing or incorrect address information, and $14(1.5 \%)$ lived in counties that were not contiguous to Hillsborough County.

${ }^{\mathrm{b}}$ Although the urine specimens were tested for opiates and amphetamines, very few youths were found to be positive for these drugs $(0.5 \%$ and $1.8 \%)$, respectively. Hence, these drugs were excluded from our analyses.
Youths who receive DRAI scores of 0 to 6 are released back into the community and are assigned diversion. Youth receiving a score of 7 to 11 are placed under the supervision of the DJJ in non-secure home detention (ie, house arrest). Youth receiving scores of 12 or higher are placed under DJJ supervision in secure detention. For both types of DJJ supervised youth, they are assigned a DJJ case manager who monitors their case until final court disposition. The current charge level dichotomy used in our analyses differentiated diversion eligible youths (DRAI score 0 to 6 points) from youths whose scores placed them under the supervision of DJJ (7 points or higher).

\section{Number of prior arrests}

This variable represents the number of arrests each youth had prior to the arrest/charge resulting in admission to the HJAC. This includes arrests for felony and misdemeanor charges, as well as violent, property, public disorder, and/or noncriminal arrests (eg, violation of probation). This information was obtained via the Department of Juvenile Justice's tracking system (JJIS).

\section{Age at first arrest}

Based on the information gathered from JJIS, age at first arrest was calculated according to the youth's birthday and the date of the youth's first arrest.

\section{Days in secure custody}

This variable represents the number of days prior to the current HJAC admission that the youth was in detention, a secure residential facility, or in other secure placements in Florida prior to their admission to HJAC. This information was also obtained via the DJJ's JJIS database.

\section{Community-level risk factors}

Census tract boundaries for 2000 serve as the unit of analysis for the community. Census tracts represent geographic regions established by the US Census Bureau that are relatively homogeneous areas with respect to demographic and economic characteristics, containing anywhere from 1500 to 8000 people, but optimally 4000 people. In 2000, there were 249 census tracts in Hillsborough County. A total of $n=202(88 \%)$ Hillsborough County census tracts contained at least one study youth. Furthermore, an additional 19 census tracts within counties adjacent to Hillsborough County contained at least 1 study youth. Thus, measures for a total of 221 census tracts were included in the analyses.

The decision to use census tracts as the geographic unit of analysis for community-level variables, rather than 
block-level measures, smaller geographically contiguous sections comprising the census tracts that may correspond with the individual city blocks or a slightly larger area, was informed by conceptual issues of aggregation bias when estimating effects, ${ }^{45}$ and the distribution of the community level data analyzed. Conceptually, racial/ethnic heterogeneity has been found to be robust at the census tract level in explaining key constructs of social disorganization theory, and measures of broken homes and disadvantage have been found to be associated with higher perceptions of crime at both the block and census tract levels. ${ }^{45}$ Further, the distribution of our sample cases within census tracts limited the ability to adequately perform block-level analyses. Of the 221 tracts in which the sample resided, 103 (46\%) contained only 1 or 2 youths. Use of block-level community measures would have substantially increased the number of blocks containing few, if any, cases (for a general discussion on this issue, see Hipp). ${ }^{45}$

The community measures were created using data from the 2000 census population and housing data at the tract-level. While the US Census provides annual updates of population estimates, this information is limited (ie, only provides total population, gender, and race/ethnicity counts). To examine more detailed household characteristics, researchers are limited to using the 2000 census figures. While this results in a 6-year lag between the community and individual characteristics examined in this study, these data are the most current data available. Each tract-level measure was coded as a continuous variable, using logarithmic transformations of these variables, where indicated, in the analyses. For variables with the lowest kurtosis, transforming the data was not necessary. For skewed variables with high kurtosis due to extreme values, a logarithmic transformation was used to reduce the extent of non-normality, while preserving the continuous nature of the variable.

\section{Community disadvantage}

Informed by the work of Sampson et $\mathrm{al}^{46}$ and Browning et $\mathrm{al},{ }^{29}$ an index was created involving four socio-economic indicators of disadvantage: the proportion of the population below the poverty line $(M=0.139, \mathrm{SD}=0.117)$, the proportion of Black residents $(M=0.174, \mathrm{SD}=0.225)$, the proportion of residents unemployed $(M=0.04, \mathrm{SD}=0.071)$, and the proportion of female headed households with children $(M=0.084$, $\mathrm{SD}=0.058)$. Three variables, the proportion of female headed households with children, proportion unemployed, and proportion living below the poverty level, with high kurtosis values (ie, $\geq 5.0$ ) were log transformed at the census tract level for use in the analyses. After transformation, the correlations among the four variables were significant. Confirmatory factor analysis indicated that a one-factor solution fit the data best $\left(\chi^{2}[2, N=221]=1.823, P=0.40\right)$. Therefore, this community level factor, reflecting concentrated disadvantage, was included in subsequent analyses.

\section{Ethnic heterogeneity}

Similar to Sampson and Groves, ${ }^{24}$ among others, a measure of ethnic heterogeneity was included as an indicator of social disorganization. This construct was intended to measure potential ethnic/racial barriers existing within each tract. Ethnic heterogeneity was calculated as one minus the sum of the squared proportion of each given race/ethnic group in each census tract's population (see Blau). ${ }^{47}$ Values of zero indicated complete ethnic homogeneity; values of one indicated complete maximum heterogeneity $(M=0.326$, $\mathrm{SD}=0.159)$.

\section{Hispanic}

The proportion of the population identifying themselves as Hispanic in 1999 was also included in the analyses $(M=0.166, \mathrm{SD}=0.128)$.

\section{Youth 12 to 18}

The size of the adolescent population residing in a census tract was measured by the proportion of the population between 12 and 18 years of age in $1999(M=0.342$, $\mathrm{SD}=0.042)$.

\section{Divorced}

The proportion of the population 15 years of age or older reporting they were divorced $(M=0.124, \mathrm{SD}=0.039)$ was also included in the analyses.

\section{Less than high school education}

A variable representing the proportion of the population 25 years of age and above with less than a high school education $(M=0.226, \mathrm{SD}=0.138)$ was also included in the analyses.

\section{Residential stability}

This variable represented the proportion of the population five years old and over living in the same house five years earlier to $1999(M=0.472, \mathrm{SD}=0.126)$.

\section{Urban}

Finally, an indicator for the proportion of the population residing in an urban area $(M=0.922, \mathrm{SD}=0.206)$ was created. The census data specify the population distributions 
in "urban," "rural," and "suburban" areas. We relied on the urban specification indicated in the 2000 census data. This specification is based on whether an area has a population density of 500 people or more per square mile. Due to its high kurtosis value, this variable was logarithmically transformed. The transformation occurred in three steps: (1) subtracting the variable values from $1,(2)$ taking the logarithm of this converted variable, and then (3) multiplying the result of step two by -1 . This new variable, reflecting urban location, was used in our analyses.

\section{Analysis strategy}

The data were collected at only one facility, which served a single county, which limited the generality of these results. For this reason, we did not apply the commonly employed hierarchical mixed models or other random effects models that generalize from the observed communities to a population of communities, to disentangle the effects of the community-level and individual-level variables. Instead, we considered the simpler question of the association of each predictor variable separately, not controlling for variables other than gender (by analyzing males and females separately) and race (by using two-way analysis).

The analyses begin with separate comparisons of all subjects by gender and by STD status on demographic characteristics, charge level, post HJAC placement, and substance use. In view of gender difference in STD status, two-way multivariate analyses of variance (MANOVA) for individuallevel and community-level variables, by STD status and race, were performed for males and females, separately. In these analyses, the main effect for STD status indicates the extent to which youths with or without STD differ on individuallevel and community-level variables, controlling for differences in race. The main effect of race indicates the extent to which African-American and non-African-American youths differ, controlling for STD status; this comparison was not relevant to the purposes of this paper, so it is not discussed. The interaction of STD and race indicates the extent to which African-American and non-African-American youths differ in their associations of STD status with individual-level and community-level variables.

Each of these multivariate comparisons provided an overall test of significance for all 15 individual-level and community-level variables. Only when the overall test was significant $(P<0.05)$, were results for the separate risk factors also presented. This protects against problems of multiple comparisons in the same sense as Fisher's "protected" LSD test. A rigorous adjustment for multiple comparisons is use of the Bonferroni inequality. If each of the 15 individual-level or community-level risk factors is tested at the $0.05 / 15=0.0033$ level of significance, the probability that one or more will be significant by chance is no more than 0.05. Parallel to each multivariate analysis, separate two-way univariate analyses of variance (ANOVA) examined the effects of each of the individual-level and community-level risk factors.

It is important to note that two-way MANOVA and ANOVA tests of significance for STD status differences control for race differences and the interaction of STD status with race. In contrast, the descriptive statistics presented for each risk factor, comparing youths with and without STD, do not control for race.

\section{Weighting to counteract over-enrollment of females}

Although females were over-enrolled in the study, most analyses were performed without weighting the data. All multivariate analyses of variance were performed for males and females separately, so the respective samples were representative of the gender sub-populations. Sampling males and females at different rates affects the power of the preliminary comparisons between genders, but it does not affect the discrepancy between the male and female distributions for any variable. Preliminary comparisons of subjects on STD status, however, did weight the data. During the enrollment period for the study, 1.9 arrested males for every 1 arrested female were brought to the assessment center. Therefore, when comparing the entire sample, we weighted males by 1.233 and females by 0.736 , so that the total sample was still 924, but the weighted samples of 605 males and 319 females had the correct proportion (1.9:1). Without weighting the sample, these analyses would have included similar numbers of male (493) and female (431) subjects and provide inaccurate infection rates for HJAC youth.

\section{Results}

\section{Overall comparisons by gender}

Table 1 compares the youths by gender. The male and female youths were similar in age and in race. On the other hand, a significantly larger percentage of females were arrested on less serious (misdemeanor, diversion eligible) charges than the males. Correspondingly, nearly 3 out of 4 females, compared to just over half of the males, were released to the community, while more males than females were placed on house arrest or sent to secure detention. In regard to drug 
Table I Comparison of male and female sociodemographic characteristics, charge level, and post HJAC placement (unweighted sample)

\begin{tabular}{|c|c|c|c|}
\hline Variables & $\begin{array}{l}\text { Female } \\
(n=430-43 I)\end{array}$ & $\begin{array}{l}\text { Male } \\
(n=492-493)\end{array}$ & Statistics \\
\hline \multicolumn{4}{|l|}{ Race/Ethnicity } \\
\hline Non-African-American & $50.3 \%$ & $46.5 \%$ & \multirow[t]{2}{*}{$\chi^{2}(1)=1.40, P=\mathrm{ns}$} \\
\hline African-American & $49.7 \%$ & $53.5 \%$ & \\
\hline \multicolumn{4}{|l|}{ Age } \\
\hline 12 & $3.7 \%$ & $2.4 \%$ & \multirow{7}{*}{$\begin{array}{l}\chi^{2}(6)=6.10, P=\mathrm{ns} \\
\mathrm{t}(922)=-1.89, P=\mathrm{ns}\end{array}$} \\
\hline 13 & $9.7 \%$ & $9.3 \%$ & \\
\hline 14 & $16.2 \%$ & $13.2 \%$ & \\
\hline 15 & $20.2 \%$ & $18.7 \%$ & \\
\hline 16 & $23.9 \%$ & $25.2 \%$ & \\
\hline 17 & $22.3 \%$ & $27.8 \%$ & \\
\hline 18 & $3.9 \%$ & $3.4 \%$ & \\
\hline \multicolumn{4}{|l|}{ Charge level } \\
\hline Diversion & $72.2 \%$ & $58.5 \%$ & \multirow[t]{2}{*}{$\chi^{2}(1)=18.71, P<0.001$} \\
\hline Department of Juvenile Justice Case & $27.8 \%$ & $41.5 \%$ & \\
\hline \multicolumn{4}{|l|}{ Post HJAC placement } \\
\hline Diversion & $72.2 \%$ & $55.3 \%$ & \multirow[t]{3}{*}{$\chi^{2}(2)=28.44, P<0.001$} \\
\hline Non-secure home detention & $10.2 \%$ & $17.9 \%$ & \\
\hline Secure detention & $17.6 \%$ & $26.8 \%$ & \\
\hline \multicolumn{4}{|l|}{ Drug test results } \\
\hline Marijuana positive & $27.0 \%$ & $42.9 \%$ & $\chi^{2}(I)=25.38, P<0.00 I$ \\
\hline Cocaine positive & $4.0 \%$ & $6.1 \%$ & $\chi^{2}(I)=2.18, P=\mathrm{ns}$ \\
\hline \multicolumn{4}{|l|}{ STD positive } \\
\hline Full sample & $19.7 \%$ & $10.8 \%$ & $\chi^{2}(I)=|4.57, P<0.00|$ \\
\hline African-American youth $(n=478)$ & $28.5 \%$ & $15.9 \%$ & $\chi^{2}(I)=11.09, P<0.001$ \\
\hline Non-African-American youth $(n=446)$ & $11.1 \%$ & $4.8 \%$ & $\chi^{2}(I)=6.03, P<0.014$ \\
\hline
\end{tabular}

Notes: Percentages are reported in the chi-square cells for ease of interpretation, rather than frequencies. Frequency breakdown for this table are available upon request. Abbreviations: HJAC, Hillsborough County Juvenile Assessment Center; STD, sexually transmitted disease.

use, the males had a significantly higher marijuana positive rate, than the females. No significant gender differences were found for the cocaine test result. Significant differences were found for STD status in regard to gender, with nearly $20 \%$ of the girls, but only $11 \%$ of the boys, being STD positive. Similar differences between males and females were also found for African-American youths only and non-AfricanAmerican youths.

\section{Overall comparison by STD status}

Table 2 compares the demographic, HJAC processing characteristics, and UA drug test results, for the STD positive and STD negative youths using weighted data. The weighted data were used to provide the correct probability of infection across gender for the HJAC population during the duration of the project. Similar race differences were found among females only and among males only. STD positive youths were significantly older than STD negative youths. Youths arrested on more serious charges and youths placed in secure detention were significantly more likely to be STD positive, than youths arrested on misdemeanor, diversion eligible charges or youths placed in diversion or non-secure home detention. Furthermore, as Table 2 shows, youths who tested positive for marijuana or for cocaine had significantly higher STD positive rates, than youths who tested negative for these drugs.

\section{MANOVAs for individual- and community- level variables by STD status and the interaction of STD status with race}

As Table 3 shows, two-way MANOVA within each gender group found significant main effects for STD test results within each gender group. In addition, a significant race $\mathrm{x}$ STD status interaction was found for the male youths, but 
Table 2 Relationship between demographic, HJAC processing, drug and STD test results (weighted sample) ${ }^{\mathrm{a}}$

\begin{tabular}{|c|c|c|c|c|}
\hline Variables & $\mathbf{n}$ & STD negative & STD positive & Statistics \\
\hline \multicolumn{5}{|l|}{ Gender } \\
\hline Male & 605 & $89.4 \%$ & $10.6 \%$ & \multirow[t]{2}{*}{$\chi^{2}(1)=\mid 3.91, P<0.001$} \\
\hline Female & 319 & $80.6 \%$ & $19.4 \%$ & \\
\hline \multicolumn{5}{|l|}{ Race } \\
\hline African-American & 476 & $80.0 \%$ & $20.0 \%$ & \multirow[t]{2}{*}{$\chi^{2}(I)=33.3 I, P<0.00 I$} \\
\hline Non-African-American & 448 & $93.1 \%$ & $7.9 \%$ & \\
\hline \multicolumn{5}{|l|}{ Females only } \\
\hline African-American & 157 & $72.0 \%$ & $28.0 \%$ & \multirow[t]{2}{*}{$\chi^{2}(I)=14.57, P<0.001$} \\
\hline Non-African-American & 162 & $88.9 \%$ & $11.1 \%$ & \\
\hline \multicolumn{5}{|l|}{ Males only } \\
\hline African-American & 320 & $84.1 \%$ & $15.9 \%$ & \multirow[t]{2}{*}{$\chi^{2}(I)=19.23, P<0.001$} \\
\hline Non-African-American & 286 & $95.1 \%$ & $4.9 \%$ & \\
\hline Age (SD) & 924 & I5.4 (I.49) & $15.9(1.33)$ & $\mathrm{F}(1,332)=12.35, P<0.001$ \\
\hline \multicolumn{5}{|l|}{ Charge level } \\
\hline Diversion case & 582 & $89.9 \%$ & $10.1 \%$ & \multirow[t]{2}{*}{$\chi^{2}(I)=16.50, P<0.001$} \\
\hline Department of Juvenile Justice case & 341 & $80.4 \%$ & $19.6 \%$ & \\
\hline \multicolumn{5}{|l|}{ Post HJAC placement } \\
\hline Diversion & 563 & $89.5 \%$ & $10.5 \%$ & \multirow[t]{3}{*}{$\chi^{2}(2)=17.40, P<0.001$} \\
\hline Non-secure detention & 139 & $87.1 \%$ & $12.9 \%$ & \\
\hline Secure detention & 220 & $78.2 \%$ & $21.8 \%$ & \\
\hline \multicolumn{5}{|l|}{ Drug test results } \\
\hline \multicolumn{5}{|l|}{ Marijuana } \\
\hline Negative & 578 & $88.1 \%$ & $11.9 \%$ & \multirow[t]{2}{*}{$\chi^{2}(I)=3.47, P=0.06$} \\
\hline Positive & 344 & $83.7 \%$ & $16.3 \%$ & \\
\hline \multicolumn{5}{|l|}{ Cocaine } \\
\hline Negative & 873 & $86.8 \%$ & $13.2 \%$ & \multirow{2}{*}{$\chi^{2}(I)=2.07, P=\mathrm{ns}$} \\
\hline Positive & 49 & $79.6 \%$ & $20.4 \%$ & \\
\hline
\end{tabular}

Notes: Percentages are reported in the $\chi^{2}$ cells for ease of interpretation, rather than frequencies. Frequency breakdown for this table are available upon request. a Males were weighted 1.233 and females weighted 0.736 , resulting in a sample size of 924 , but with the weighted sample of 605 males and 319 females having the correct proportion (1.90:1).

${ }^{\mathrm{b} D o e s}$ not total 605 cases due to rounding of cell counts.

Abbreviations: HJAC, Hillsborough County Juvenile Assessment Center; STD, sexually transmitted disease.

not for female youths. The subsequent tables present mean values for subgroups that indicate in which directions the subgroups differ on each risk factor, and univariate analyses of these differences for each risk factor.

\section{Comparing STD-positive and STD-negative females}

Univariate results are reported due to the significant STD test result differences in females reported in the overall MANOVA results in Table 3 (at $P<0.05$ level). As Table 4 shows, several significant, individual-level effects were found when STD-positive and STD-negative females were compared on the individual- and community-level factors. STD-positive females averaged over twice as many prior arrests as STD-negative females. STD-positive females were significantly more likely to be older, charged with a more serious offense, test positive for marijuana and cocaine, and have more prior arrests, than STD-negative females. No significant community-level variable effects were found among females.

\section{Comparing STD-positive and STD-negative Males}

Similar to race, the overall MANOVA results in Table 3 indicated significant differences in individual- and communitylevel predictors of STD status among boys. A number of important relationships were found between the individuallevel factors and STD results for the males. Similar to the 
Table 3 MANOVA overall model results for independent variables of race, STD test result, and their interaction, separately by gender (unweighted sample)

\begin{tabular}{lc}
\hline Females $(\mathbf{n}=\mathbf{4 2} \mathrm{I})$ & F-ratio $(\mathbf{d f}=\mathbf{I 5}, \mathbf{4 0 3})$ \\
Race & $\mathrm{I} .54 *$ \\
STD test result & $2.96 * * * *$ \\
Race $\times$ STD test result & 0.93 \\
Males $(\mathbf{n}=\mathbf{4 8 3})$ & F-ratio $(\mathbf{d f}=\mathbf{I 5}, \mathbf{4 6 5})$ \\
Race & $1.97 * *$ \\
STD test result & $2.69 * * * *$ \\
Race $\times$ STD test result & $2.22 * * *$ \\
\hline
\end{tabular}

Notes: Dependent variables are age, current charge level, marijuana test result, cocaine test result, prior arrests, age of first arrest, days in secure custody, concentrated disadvantage, ethnic heterogeneity, Hispanic, youth 12 to 18 , less than high school education, residential stability, and urban.

Significance levels: $* 0.10>P>0.05 ; * * P<0.05$; ***P $<0.01$; **** $* 0.001$.

Abbreviation: STD, sexually transmitted disease.

females included in the study (Table 4), as Table 5 shows, STD-positive males were significantly more likely to be older, arrested on a more serious charge, and to have more prior arrests, than STD-negative males. In contrast to the results for the girls, no significant effects were found for the marijuana and cocaine test results. Among community level factors, STD-positive males were significantly more likely to live in census tracts with higher divorce rates, compared to STD-negative males.

\section{Interaction of race $\times$ STD test results for the males}

Finally, Table 6 displays the results of the race $\times$ STD interaction analysis involving the individual- and community-level variables for the male youths. ${ }^{c}$ No significant individual-level interactions were found. In regard to community-level factors, however, among STD positive youths, African-Americans were significantly more likely to live in census tracts characterized by concentrated disadvantage than non-African-Americans, without a corresponding difference for STD-negative youths. Further, non-AfricanAmerican, STD-positive youths were more likely to live in census tracts with higher divorce rates, than youths in the other three groups.

\section{Discussion}

The goal of the current study was to explore the similarities and differences in the risk factors for STD infection across

${ }^{\mathrm{c}}$ Referring back to Table 3, a significant race-STD interaction was not found for the females included in the study. Therefore, further assessment of this relationship was not conducted. race and gender subgroups of newly arrested juvenile offenders. Our results highlighted important similarities, as well as differences, in the risk factors for STD infection across race and gender when examined separately. Most importantly, however, a significant interaction between race and STD status was found for the newly arrested males, but not females, included in the sample. Results examining the risk factors that may account for this interaction highlighted important community-level differences. Specifically, the African-American, STD-positive males were more likely to reside in areas characterized by concentrated disadvantage, whereas the non-African-American, STD-positive males were more likely to reside in areas characterized by a higher proportion of divorced residents, compared to the other three groups. Interestingly, no significant individual-level differences were found across the race-STD male subgroups.

A number of important prevention and treatment implications can be drawn from this study. Overall, it seems that understanding STD infection among juvenile offenders requires an approach that targets the specific needs of demographic subgroups of at-risk youth. For example, our results revealed important differences in the association among substance use and STD infection across gender. For males, testing positive for marijuana and cocaine was not an important risk factor for STD infection. STD-positive females, however, were significantly more likely to test marijuana and cocaine positive compared to STD negative females. For females, intervention programs that target adolescent substance use may be particularly effective in reducing STD infection. One component of many substance abuse prevention programs is to educate youth on the negative consequences of using substances. Our findings suggest that, for females, STD infection may be one potential consequence of substance use. Therefore, substance use prevention programs represent an effective avenue to provide at-risk females with lessons on sexual responsibility, but may not prove as effective for at-risk male adolescents. This finding underscores the importance of gender-specific programs targeting sexual health and well-being.

Our study also highlights the important influence that community context has on adolescent well-being. Not only does our study underscore the importance of simultaneously considering the individual- and community-level risk factors for STD infection, it also brings to light the importance of considering these risk factors across race and gender subgroups. Important differences in the communitylevel risk factors for STD infection were found across race and gender. For example, the interaction of race and STD 
Table 4 Comparison of STD positive and STD negative females on the individual- and community-level variables (unweighted sample)

\begin{tabular}{|c|c|c|c|c|c|}
\hline & \multicolumn{2}{|c|}{$\begin{array}{l}\text { STD positive } \\
(\mathrm{n}=\mathbf{8 2})\end{array}$} & \multicolumn{2}{|c|}{$\begin{array}{l}\text { STD negative } \\
(n=339)\end{array}$} & \multirow[t]{2}{*}{$\begin{array}{l}\text { F-ratio } \\
(\mathrm{df}=1,4 \mid 8)^{\mathrm{b}}\end{array}$} \\
\hline & Mean & SE & Mean & SE & \\
\hline \multicolumn{6}{|l|}{ Individual-level variables ${ }^{a}$} \\
\hline Age & 15.66 & 0.15 & 15.25 & 0.08 & $5.57 * *$ \\
\hline Current charge level & 1.40 & 0.05 & 1.25 & 0.02 & $5.90 * *$ \\
\hline Marijuana test result & 0.35 & 0.05 & 0.25 & 0.02 & $6.11^{* *}$ \\
\hline Cocaine test result & 0.07 & 0.03 & 0.03 & 0.01 & $6.53 * *$ \\
\hline Number of prior arrests & 2.38 & 0.37 & 1.06 & 0.10 & $22.61 * * * *$ \\
\hline Age at first arrest & $|4.2|$ & 0.21 & 14.38 & 0.09 & 0.21 \\
\hline Days in secure custody & 10.83 & 2.58 & 8.77 & 3.13 & 0.10 \\
\hline \multicolumn{6}{|l|}{ Community-level variables } \\
\hline Concentrated disadvantage & 0.07 & 0.10 & 0.05 & 0.05 & 0.01 \\
\hline Ethnic heterogeneity & 0.37 & 0.02 & 0.38 & 0.01 & 1.51 \\
\hline Hispanic & 0.18 & 0.02 & 0.16 & 0.01 & 0.00 \\
\hline Youth 12 to 18 & 0.34 & 0.00 & 0.34 & 0.01 & 0.08 \\
\hline Divorced & 0.14 & 0.00 & 0.13 & 0.00 & 0.82 \\
\hline Less than high school & 0.31 & 0.02 & 0.29 & 0.01 & 0.22 \\
\hline Residential stability & 0.50 & 0.01 & 0.47 & 0.01 & $3.5 I^{*}$ \\
\hline Urban & -0.22 & 0.06 & -0.21 & 0.03 & 0.03 \\
\hline Overall $\mathrm{F}(\mathrm{df}=15,403)=2.96^{* * * * *}$ & & & & & \\
\hline
\end{tabular}

Notes: Significance levels: $* 0.10>P>0.05 ; * * P<0.05 ; * * * P<0.01$; ****P $<0.001$.

a Means and standard errors are not corrected for any relationships with race.

${ }^{\mathrm{b}}$ Adjusted for any relationships with race.

Abbreviation: STD, sexually transmitted disease.

status for the males, but not females, was influenced by community-, but not individual-level, factors. Thus, failing to account for these community-level factors would have led to an incomplete understanding of the risk factors for STD status across race and gender subgroups of newly arrested juvenile offenders.

As described in earlier sections of this paper, the structural characteristics of a neighborhood have the potential to influence adolescent behavior in a number of ways including the availability of community resources and the level of informal social control.22,26,48 Our results suggest that different contextual mechanisms may influence sexual health differently for African-American male adolescents compared to non-African-American male adolescents. For African-American male youth included in our study, it seems that economic disadvantage in the community was related to STD status. Residents residing in such areas are less likely to have access to affordable health care, community resources, free sexual education, testing services, and contraception.

This finding has significant implications for the juvenile justice system and other community organizations. For many at-risk youth who do not have access to health services, the
JJS may serve as the first means of detecting STD infection and the only available resource for providing STD treatment and prevention. Other than the JJS, the public school system may be one of the only resources for STD detection and prevention available to youth who reside in disadvantaged communities. Our findings suggest that the juvenile justice system needs to take a proactive role in affecting public health. Juvenile justice policy makers should seriously consider how they can improve STD treatment and prevention, including collaboration with various community health and education organizations.

For the non-African-American males included in the sample, proportion of divorced residents was an important risk factor for STD infection. This finding suggests that neighborhood monitoring and supervision may play an important role in STD infection for this subgroup of adolescents. It is often suggested that neighborhoods with a high level of family disruption are unable to provide effective supervision of neighborhood youth. Single adults are more likely to work long hours, experience economic strain, and provide inconsistent supervision in the home. ${ }^{24,48}$ This has the potential to lead to higher levels of unsupervised socializing, 
Table 5 Comparison of STD positive and STD negative males on the individual- and community-level variables (unweighted sample)

\begin{tabular}{|c|c|c|c|c|c|}
\hline & \multicolumn{2}{|c|}{$\begin{array}{l}\text { STD positive } \\
(\mathrm{n}=52)\end{array}$} & \multicolumn{2}{|c|}{$\begin{array}{l}\text { STD negative } \\
(n=431)\end{array}$} & \multirow[t]{2}{*}{$\begin{array}{l}\text { F-ratio } \\
(\mathrm{df}=\mathrm{I}, 479)\end{array}$} \\
\hline & Mean & SE & Mean & SE & \\
\hline \multicolumn{6}{|l|}{ Individual-level variables ${ }^{\mathbf{a}}$} \\
\hline Age & 16.14 & 0.23 & 15.44 & 0.10 & $9.19 * * *$ \\
\hline Current charge level & 1.67 & 0.09 & 1.39 & 0.03 & $8.54 * * *$ \\
\hline Marijuana test result & 0.52 & 0.10 & 0.42 & 0.03 & 1.03 \\
\hline Cocaine test result & 0.08 & 0.05 & 0.06 & 0.02 & 0.40 \\
\hline Number of prior arrests & 4.37 & 0.87 & 2.43 & 0.22 & $5.38 * *$ \\
\hline Age at first arrest & 13.44 & 0.44 & $13.9 \mid$ & 0.14 & $\mathrm{I} .33$ \\
\hline Days in secure custody & 79.94 & 33.40 & 31.20 & 7.55 & 1.88 \\
\hline \multicolumn{6}{|l|}{ Community-level variables } \\
\hline Concentrated disadvantage & 0.10 & 0.18 & -0.07 & 0.06 & 0.05 \\
\hline Ethnic heterogeneity & 0.38 & 0.04 & 0.38 & 0.01 & 0.42 \\
\hline Hispanic & 0.17 & 0.03 & 0.17 & 0.01 & 0.62 \\
\hline Youth 12 to 18 & 0.34 & 0.01 & 0.34 & 0.00 & 0.10 \\
\hline Divorced & 0.14 & 0.01 & 0.13 & 0.00 & $5.53 * *$ \\
\hline Less than high school & 0.29 & 0.03 & 0.27 & 0.01 & 0.02 \\
\hline Residential stability & 0.49 & 0.03 & 0.48 & 0.01 & 0.91 \\
\hline Urban & -0.11 & 0.08 & -0.23 & 0.04 & $2.82 *$ \\
\hline Overall $\mathrm{F}(\mathrm{df}=15,465)=2.53^{* * * *}$ & & & & & \\
\hline
\end{tabular}

Notes: Significance levels: $* 0.10>P>0.05 ; * * P<0.05$; ***P $<0.01$; **** $P<0.001$.

a Means and standard errors are not corrected for any relationships with STD test results.

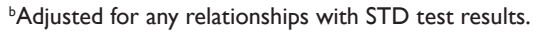

Abbreviation: STD, sexually transmitted disease.

misbehavior that goes unnoticed and undetected, and negative role modeling. In sum, greater levels of family disruption in a community have the potential to indirectly influence adolescent sexual behavior, perhaps through weakened informal social control mechanisms.

Thus, it is possible that African-American male youth residing in disadvantaged areas are not necessarily engaging in higher levels of sexual risk-taking, but instead, have lower access to testing and treatment services. In contrast, for the non-African-American males included in the sample, lower levels of social control due to a higher number of single parent families residing in the neighborhood may be influencing the tendency for this subgroup of adolescents to engage in higher levels of risk behaviors. Unfortunately, asking the participants to describe the social control mechanisms, or prevention and treatment services, that existed in their neighborhood was beyond the scope of the original study. Future research is needed to fully understand the mechanisms operating at the community-level, as well as the interaction between community characteristics and demo- graphic characteristics, that lead to differences in STD status across race and gender. This research will serve to inform methods of community-level and individual-level treatment and prevention. Clearly, the findings from this study suggest that a multilevel intervention for STD infection designed to be gender specific is warranted for justice-involved youth. More specifically, for females, this prevention should include components for substance use and recidivism; while for males, this prevention should include components on recidivism and community support.

With regard to the interaction between STD status and race, this study indicated that a multivariate model is necessary for understanding the effects of STD and antisocial risk factors on race and STD status for males but not females. As discussed, the literature on STD infection rates consistently finds a strong association with race and gender. The univariate analyses examined the hypotheses that individual-level attributes such as substance use and criminal history and community-level characteristics of disadvantage predicted STD status, but that this status also depend on race and gender. For females, our results 
Table 6 Interaction of race and STD results for male youth: means (unweighted sample, standard errors in parentheses)

\begin{tabular}{|c|c|c|c|c|c|}
\hline & $\begin{array}{l}\text { Non-African-American, } \\
\text { STD negative } \\
(\mathrm{n}=2 \mid 2)\end{array}$ & $\begin{array}{l}\text { Non-African-American, } \\
\text { STD positive } \\
(\mathrm{n}=10)\end{array}$ & $\begin{array}{l}\text { African-American, } \\
\text { STD negative } \\
(n=219)\end{array}$ & $\begin{array}{l}\text { African-American, } \\
\text { STD positive } \\
(n=42)\end{array}$ & $\begin{array}{l}\text { F-ratio } \\
(\mathrm{df}=1,479)^{a}\end{array}$ \\
\hline \multicolumn{6}{|l|}{ Individual-level variables } \\
\hline Age & $15.68(0.10)$ & $16.40(0.56)$ & $15.20(0.01)$ & $16.07(0.17)$ & 0.09 \\
\hline Current charge level & $1.34(0.03)$ & $1.60(0.16)$ & $\mathrm{I} .43(0.03)$ & $1.69(0.07)$ & 0.00 \\
\hline Marijuana test result & $0.44(0.03)$ & $0.50(0.17)$ & $0.40(0.03)$ & $0.52(0.08)$ & 0.11 \\
\hline Cocaine test result & $0.08(0.02)$ & $0.10(0.10)$ & $0.04(0.01)$ & $0.07(0.04)$ & 0.03 \\
\hline Number of prior arrests & $\mathrm{I} .87(0.2 \mathrm{I})$ & $3.10(1.02)$ & $2.97(0.24)$ & $4.67(0.74)$ & 0.13 \\
\hline Age at first arrest & $14.33(0.14)$ & I $3.50(0.56)$ & $13.50(0.15)$ & I3.43(0.38) & 0.95 \\
\hline Days in secure custody & $35.79(7.67)$ & $32.00(23.10)$ & $26.76(5.34)$ & 91.36 (29.32) & 2.38 \\
\hline \multicolumn{6}{|l|}{ Community-level variables } \\
\hline Concentrated disadvantage & $-0.07(0.07)$ & $-0.46(0.30)$ & $-0.08(0.07)$ & $0.23(0.14)$ & $4.05^{* *}$ \\
\hline Ethnic heterogeneity & $0.39(0.01)$ & $0.33(0.06)$ & $0.37(0.01)$ & $0.39(0.03)$ & 1.21 \\
\hline Hispanic & $0.17(0.01)$ & $0.13(0.04)$ & $0.17(0.01)$ & $0.18(0.03)$ & 0.68 \\
\hline Youth 12 to 18 & $0.34(0.00)$ & $0.34(0.01)$ & $0.34(0.00)$ & $0.34(0.01)$ & 0.00 \\
\hline Divorced & $0.13(0.00)$ & $0.16(0.01)$ & $0.13(0.00)$ & $0.13(0.01)$ & $5.76 * *$ \\
\hline Less than high school & $0.26(0.01)$ & $0.25(0.04)$ & $0.29(0.01)$ & $0.31(0.02)$ & 0.33 \\
\hline Residential stability & $0.48(0.01)$ & $0.50(0.04)$ & $0.48(0.01)$ & $0.49(0.02)$ & 0.21 \\
\hline Urban & $-0.19(0.03)$ & $0.00(0.00)$ & $-0.27(0.04)$ & $-0.14(0.07)$ & 0.12 \\
\hline Overall $F(d f=15,465)=2.23 * *$ & & & & & \\
\hline
\end{tabular}

Notes: Significance Levels: $* 0.10>P>0.05 ; * * P<0.05 ; * * * P<0.01 ; * * * * P<0.001$.

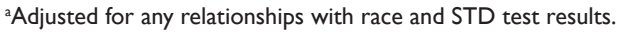

Abbreviation: STD, sexually transmitted disease.

showed STD positive girls possessed significantly higher levels of individual and community risk factors for antisocial behavior, and African-American girls possessed elevated but only marginally significant risk factors. It is interesting that the bivariate relationship between race and STD status for females is highly significant (Table 2), whereas the multivariate analysis results reported in Table 3 indicate a marginally significant effect. This difference in results is likely the result of the inclusion of additional variables in the MANOVA model. For males, our study indicated African-American and STD positive boys had significantly higher risk factors, and race and STD status were highly correlated. Indeed, once the multivariate nature of STD status and race were accounted for, the individual risk factors became non-significant and only community characteristics mattered in predicting differences in STD infection rates. These results suggest that risk factors for STD infection work differently for white boys than African-American boys, but similarly for girls, regardless of race. Replication of the study is needed to validate its findings and offer further insight into why this multivariate relationship between STD status and race exists for boys.

A few additional limitations to the current study should also be mentioned. First, a large number of analyses were conducted to examine the differences in risks for each gender, according to STD status and the interaction of race and STD status. This increases the chance of making a Type 1 error. Therefore, the findings from this study should be interpreted with caution. Second, although using biological measures of substance use overcomes issues related to inaccurate self-reported information, it also has its shortcomings. For example, drug tests are only able to capture recent or current drug use, which limited the number of drug users in the sample. ${ }^{\mathrm{d}}$ The failure to include ethnicity as an additional demographic factor was also a limitation to the current study. ${ }^{e}$ Research does indicate that Hispanic adolescents represent a high-risk group for risky sexual practices, substance use, and

${ }^{\mathrm{d}}$ The short time period for which drug use is detectable in urine is one important limitation to relying on drug test results as a measure of substance use. For heavy users, marijuana only stays in a youth's system for approximately 20 days and cocaine remains in the system for less than four days. ${ }^{57}$ ${ }^{\mathrm{e}} \mathrm{As}$ a result of the data collection procedures, as well as HIPAA safeguards prohibiting the research team to see any confidential information, the participant's ethnicity was unable to be collected in a valid manner. For example, descriptive analysis indicated that less than $10 \%$ of the final sample was Hispanic. Given that over $26 \%$ of the population between the ages of 10 and 17 in Hillsborough County is Hispanic, the proportion of study participants identified as Hispanic did not seem representative. ${ }^{58}$ 
delinquent behavior. ${ }^{49-52}$ Therefore, in addition to examining racial and gender differences in risk factors for STD infection, it is also important to identify ethnic differences. It has been suggested that Hispanic adolescents experience a different socialization process, due to ethnic differences in cultural values and expectations, family relations, and socioeconomic factors, compared to white and African-American adolescents. ${ }^{53-56}$ Thus, future research would benefit from further disaggregating the demographic subgroups examined in this study by race, gender, and ethnicity.

Moreover, the data were collected at one site, which limits the generality of these results. For this reason, we did not employ hierarchical mixed models or other random effects models to disentangle the effects of the community-level and individual-level factors. There is a need to determine if the findings obtained in this study can be replicated in centralized intake centers in other locations, serving different populations of juvenile arrestees. Further, this study was limited to examining community data gathered in the 2000 census, which resulted in a 6-year gap between the community-level characteristics and the individual-level characteristics. Future studies should attempt to collect individual-level data closer to the time of decennial census data collection to assess the generalizability of the findings of this study. Last, the data were cross-sectional which precluded the examination of the temporal sequencing of the risk factors for STD status and the timing of STD positivity. Thus, the analyses in this study focused only on the strength and direction of the association among the individual- and community-level factors and STD status; no causal statements about any of the relationships can be made. ${ }^{59}$

Despite these limitations, the results of this study provide important information to researchers and practitioners involved in the prevention and treatment of STD infection among juvenile offenders. In addition to our findings, a wealth of empirical evidence has already suggested that intervention programs that are specifically tailored and delivered to particular subgroups of adolescents are the most successful in decreasing high-risk behaviors. ${ }^{60-63}$ The reason for the effectiveness of tailored intervention programs stems from the acknowledgement that "adolescents are not a homogeneous population; rather, adolescents are a heterogeneous mosaic of subgroups of different ethnicities/cultures, behavioral risk characteristics, developmental levels, sexual preferences, and gender differences" (DiClemente, ${ }^{64}$ p. 600). Thus, adapting prevention and intervention strategies to meet the developmental, social, and ecological needs of each particular subgroup of adolescents at risk for STD infection is the most effective intervention strategy. Taking a socio-ecological approach to understanding, and more importantly preventing, STD infection among juvenile offenders will not only improve the lives of the adolescents involved, but will also improve the health and well-being of the community as a whole.

\section{Acknowledgments}

Preparation of this manuscript was supported by Grant \# DA020346, funded by the National Institute on Drug Abuse. The authors are grateful for their support; however, the research results reported and the views expressed in the paper do not necessarily imply any policy or research endorsement by our funding agency. We would also like to thank the Hillsborough County, FL Juvenile Assessment Center and the Hillsborough County Health Department.

\section{Disclosures}

The authors declare no conflicts of interest.

\section{References}

1. Centers for Disease Control and Prevention. Sexually transmitted disease surveillance 2007. Atlanta, GA: US Department of Health and Human Services, Centers for Disease and Control and Prevention. 2008 .

2. Weinstock H, Berman S, Cates W. Sexually transmitted diseases among American Youth: Incidence and prevalence estimates, 2000. Perspectives on Sexual and Reproductive Health. 2004;36:6-10.

3. Belenko S, Dembo R, Rollie M, Childs K, Salvatore C. Detecting, preventing, and treating sexually transmitted infections among adolescent offenders: An unmet public health need. American Journal of Public Health. 2008;99:1032-1041.

4. Puzzanchera C. Juvenile arrests 2007. Juvenile justice bulletin. Washington, DC: US Department of Justice, Office of Justice Programs, Office of Juvenile Justice and Delinquency Prevention. 2009.

5. Kahn RH, Mosure DJ, Blank S, et al. Chlamydia trachomatis and Neisseria gonorrhea prevalence and coinfection in adolescents entering selected US juvenile detention centers, 1997-2002. Sexually Transmitted Diseases. 2005;32(4):255-259.

6. Mertz KJ, Voigt RA, Hutchins K, Levine WC. Findings from STD screening of adolescents and adults entering corrections facilities. Sexually Transmitted Diseases. 2002;29(12):834-839.

7. Lofy KH, Hofmann J, Mosure DJ, Fine DN, Marrazzo JM. Chlamydial infections among female adolescents screened in juvenile detention centers in Washington State, 1998-2002. Sexually Transmitted Diseases. 2006;33(2):63-67.

8. Kotchick BA, Shaffer A, Forehand R, Miller KS. Adolescent sexual risk behavior: A multi-system perspective. Clinical Psychology Review. 2001;21(4):493-519.

9. Risser J, Risser WL, Gefter LR, Brandstetter DM, Cromwell PF. Implementation of a screening program for Chlamydial infection in incarcerated adolescents. Sexually Transmitted Diseases. 2001;28(1):43-46.

10. Robertson AA, Thomas CB, St. Lawrence J, Pack R. Predictors of infection with Chlamydia or Gonorrhea in incarcerated adolescents. Sexually Transmitted Diseases. 2005;32(3):115-122.

11. Shafer MA, Hilton JF, Ekstrand M, et al. Relationship between drug use and sexual behaviors and the occurrence of sexually transmitted diseases among high-risk male youth. Sexually Transmitted Diseases. 1993;20:307-313. 
12. Morris RE, Harrison EA, Knox GW, Tromanhauser E, Marquis DK, Watts LL. Health risk behavioral survey from 39 juvenile correctional facilities in the United States. Journal of Adolescent Health. 1995; 17:334-344.

13. Tolou-Shams M, Brown LK, Gordon G, Fernandez I. Arrest history as an indicator of adolescent/young adult substance use and HIV risk. Drug and Alcohol Dependence. 2007;88:87-90.

14. Robertson A, Levin ML. AIDS knowledge, condom attitudes, and risktaking sexual behavior of substance-abusing juvenile offenders on probation or parole. AIDS Education and Prevention. 1999;11(5):450-461.

15. Harwell TS, Trino R, Bret R, Yorkman S, Gollub EL. Sexual activity, substance use, and HIV/STD knowledge among detained male adolescents with multiple versus first admissions. Sexually Transmitted Diseases. 1999;26(5):265-271.

16. Crosby R, Salazar LF, DiClemente RJ, Yarber WL, Caliendo AM, Staples-Horne M. Condom misuse among adjudicated girls: Associations with laboratory confirmed Chlamydia and Gonorrhea. Journal of Pediatric Adolescent Gynecology. 2007;20:339-343.

17. Kingree JB, Phan DL. Marijuana use and HIV risk among adolescent offenders: The moderating effect of age. Journal of Substance Abuse 2001;13:59-71.

18. Oh KM, Smith KR, O’Cain M, Kilmer D, Johnson J, Hook EW. Urinebased screening of adolescents in detention to guide treatment for Gonococcal and Chlamydial infections: Translating research into intervention. Archives of Pediatrics and Adolescent Medicine. 1998;152(1):52-56.

19. Teplin LA, Mericle AA, McClelland GM, Abram KM. HIV and AIDS risk behaviors in juvenile detainees: Implications for public health policy. American Journal of Public Health. 2003;93(6):906-912.

20. Voisin DR, DiClemente RJ, Salazar LF, Crosby RA, Yaber WL. Ecological factors associated with STD risk behaviors among detained female adolescents. Social Work. 2006 ;51(3):71-79.

21. DiClemente RJ, Salazar LF, Crosby RA. A review of STD/HIV preventive interventions for adolescents: Sustaining effects using an ecological approach. Journal of Pediatric Psychology. 2007;32:888-906.

22. Leventhal T, Brooks-Gunn J. The neighborhoods they live in: The effects of neighborhood residents on child and adolescent outcomes. Psychological Bulletin. 2000;126(2):309-337.

23. Bursik RJ. Social disorganization and theories of crime and delinquency: Problems and prospects. Criminology. 1988;26:519-551.

24. Sampson RJ, Groves WB. Community structures and crime: Testing social disorganization theory. American Journal of Sociology. 1989;94:774-802.

25. Shaw CR, McKay HD. Juvenile delinquency and urban areas (rev. ed.). Chicago: University of Chicago Press; 1969.

26. Sampson RJ, Morenoff JD, Gannon-Rowley T. Assessing "neighborhood effects": Social processes and new directions in research. Annual Review of Sociology. 2002;28:443-478.

27. Baumer EP, South SJ. Community effects on youth sexual activity. Journal of Marriage and the Family. 2001;63:540-554.

28. Billy JOG, Brewster KL, Grady WR. Contextual effects on the sexual behavior of adolescent women. Journal of Marriage and the Family. 1994;56:387-404.

29. Browning CR, Leventhal T, Brooks-Gunn J. Neighborhood context and racial differences in early adolescent sexual activity. Demography. 2004;41(4):697-720.

30. South SJ, Baumer EP. Community effects on the resolution of adolescent premarital pregnancy. Journal of Family Issues. 2001;22(8): 1025-1043.

31. South SJ, Crowder KD. Neighborhood effects on family formation: Concentrated poverty and beyond. American Sociological Review. 1999;64:113-132.

32. Brewster KL. Racial differences in sexual activity among adolescent women: The role of neighborhood characteristics. American Sociological Review. 1994;59:408-424.

33. Crane J. The epidemic theory of ghettos and neighborhood effects on dropping out and teenage childbearing. American Journal of Sociology. 1991;96(5):1226-1259.
34. Driscoll AK, Sugland BW, Manlove J, Papillo AR. Community opportunity, perceptions of opportunity, and the odds of an adolescent birth. Youth and Society. 2005;37(1):33-61.

35. Brewster KL, Billy JOG, Grady WR. Social context and adolescent behavior: The impact of community on the transition to sexual activity. Social Forces. 1993;71:713-740.

36. Ku L, Sonenstein FL, Pleck J. Neighborhood, family, and work: Influences on the premarital behaviors of adolescent males. Social Forces. 1993;72:479-503.

37. Browning CR, Olinger-Wilbon M. Neighborhood disadvantage, social organization, and number of short-term sexual partnerships. Journal of Marriage and the Family. 2003;65:730-745.

38. Sucoff CA, Upchurch DM. Neighborhood context and the risk of childbearing among metropolitan-area black adolescents. American Sociological Review. 1998;63:571-585.

39. Krieger N, Waterman PD, Chen JT, Soobader M, Subramanian S. Monitoring socioeconomic inequalities in sexually transmitted infections, tuberculosis, and violence: Geocoding and choice of area-based socioeconomic measures-The Public Health Disparities Geocoding Project (US). Public Health Reports. 2003;118:240-260.

40. Shahmanesh M, Gayed S, Ashcroft M, et al. Geomapping of Chlamydia and gonorrhea in Birmingham. Sexually Transmitted Infections. 2000;76:268-272.

41. Farley TA. Sexually transmitted diseases in the southeastern United States: Location, race, and the social context. Sexually Transmitted Diseases. 2006;33:58-64.

42. Stahl A, Finnegan T, Kang W. Easy access to juvenile court statistics: 1985-2005. Retrieved on May 1:2009 from http://ojjdp.ncjrs.gov/ ojstatbb/ezajcs/. 2008

43. Chacko M, Barnes C, Wiemann C, DiClemente R. Implementation of urine testing for chlamydia (CT) and gonorrhea (NGC) in a community clinic. Journal of Adolescent Health. 2004;34:1460-153.

44. Dembo R, Turner G, Sue, CC, Schmeidler J, Borden P, Manning D. An assessment of the Florida Department of Health and Rehabilitative Services Detention Risk Assessment Instrument on Youths Screened and Processed at the Hillsborough County Juvenile Assessment Center. Journal of Child and Adolescent Abuse. 1994;4(1):45-77.

45. Hipp JR. Block, tract, and level of aggregation: Neighborhood structure and crime and disorder as a case in point. American Sociological Review. 2007;72:659-680.

46. Sampson RJ, Raudenbush SW, Earls F. Neighborhoods and violent crime: A multilevel study of collective efficacy. Science. 1997;277: 918-924.

47. Blau P. Inequality and heterogeneity. New York: Free Press; 1977.

48. Brooks-Gunn J, Duncan GJ, Klebanov PK, Sealand N. Do neighborhoods influence child and adolescent development? American Journal of Sociology. 1993;99:353-395.

49. Crepaz N, Horn AK, Rama SM, et al. The efficacy of behavioral interventions in reducing HIV risk sex behaviors and incident sexually transmitted disease in Black and Hispanic sexually transmitted disease clinic patients in the United States: A meta-analytic review. Sexually Transmitted Diseases. 2007;34:319-332.

50. Herbst JH, Kay LS, Passin WF, Lyles CM, Crepaz N, Marín BV. A systematic review and meta-analysis of behavioral interventions to reduce HIV risk behaviors of Hispanics in the United States and Puerto Rico. AIDS and Behavior. 2007;11:23-47.

51. Loue S. Preventing HIV, eliminating disparities among Hispanics in the United States. Journal of Immigration and Health. 2006;8: 313-318.

52. Ramisetty-Mikler S, Caetano R, Goebert D, Nishimura S. Ethnic variation in drinking, drug use, and sexual behavior among adolescents in Hawaii. Journal of School Health. 2004;74(1):16-22.

53. Marin G. AIDS prevention among Hispanics: Needs, risk behaviors, and cultural values. Public Health Reports. 1989;104(5):411-415.

54. McLoyd VC, Cauce AM, Takeuchi D, Wilson, L. Marital processes and parental socialization in families of color: A decade review of research. Journal of Marriage and Family. 2004;62(4):1070-1093. 
55. Pan E, Farrell MP. Ethnic differences in the effects of intergenerational relations on adolescent problem behavior in U.S. single-mother families. Journal of Family Issues. 2006;27(8):1137-1158.

56. Saint-Jean G, Crandall LA. Ethnic differences in the salience of risk and protective factors for alcohol and marijuana: Findings from a statewide survey. Journal of Ethnicity in Substance Abuse. 2004;3(1):11-27.

57. Dembo R, Shemwell M, Guida J, et al. A comparison of self-report, urine sample, and hair sample testing for drug use: A longitudinal study. In: Mieczkowski T (Ed.), Drug Testing Methods: Assessment and Evaluation. New York: CRC Press; 1999.

58. U.S. Census Bureau. 2006 American Community Survey. Retrieved on May 8, 2009 from http://factfinder.census.gov/. 2006.

59. Cook TD, Campbell DT. Quasi-experimentation: Design and analysis issues for field settings. Boston: Houghton Mifflin Company. 1979.

60. DiClemente RJ, Wingood GM, Harrington KF, et al. Efficacy of an HIV prevention intervention for African American adolescent girls: A randomized clinical trial. Journal of the American Medical Association. 2004;292:171-179.
61. Jemmott JB, Jemmott LS, Fong GT. Abstinence and safer sex HIV risk-reduction interventions for African American adolescents: A randomized clinical trial. Journal of the American Medical Association. 1998;292:1529-1536.

62. Orr DP, Langefeld CD, Katz BP, Caine VA. Behavioral intervention to increase condom use among high-risk female adolescents. Journal of Pediatrics. 1996;128:288-295.

63. St. Lawrence JS, Brasfield TL, Jefferson KW, Alleyene E, O'Bannon RE, Shirley A. Cognitive-behavioral intervention to reduce African American adolescents' risk for HIV infection. Journal of Consulting and Clinical Psychology. 1995;63:221-237.

64. DiClemente RJ, Crittenden CP, Rose E, et al. Psychosocial predictors of HIV-associated sexual behaviors and the efficacy of prevention interventions in adolescents at-risk for HIV infections: What works and what doesn't work? Psychosomatic Medicine. 2008;70:598-605.
Neurobehavioral HIV Medicine

\section{Publish your work in this journal}

Neurobehavioral HIV Medicine is an international, peerreviewed, open access journal focusing on advances in research in HIV/AIDS, with specific reference to the neurological, psychiatric and behavioral consequences of the disease, concomitant infections and specific antiretroviral therapy. The manuscript

\section{Dovepress}

management system is completely online and includes a very quick and fair peer-review system, which is all easy to use. Visit http://www.dovepress.com/testimonials.php to read real quotes from published authors. 